\title{
El exilio como fenómeno transnacional. Marcas del exilio chileno en intelectuales del Reino Unido. El Latin American Bureau (1977-2019)
}

\author{
Exile as a transnational phenomenon. Chilean exile marks in United Kingdom' intellectuals. The Latin \\ American Bureau (1977-2019)
}

\author{
Paola Adriana Bayle \\ Instituto de Ciencias Humanas, Sociales y Ambientes, INCIHUSA - CONICET \\ Universidad Nacional de Cuyo \\ paolabayle@gmail.com
}

Resumen: El presente artículo tiene como objetivo aportar a una línea de investigación en torno al exilio en tanto fenómeno transnacional. A partir del análisis del exilio chileno en tierras británicas como consecuencia del golpe militar que derrocó a Salvador Allende (1970-1973), indagaremos en las marcas que este exilio dejó entre quienes se comprometieron en actividades de solidaridad con el pueblo chileno. De manera particular, nos enfocaremos en un emprendimiento editorial nacido en 1977 en Londres, el Latin American Bureau, porque creemos que materializa las transferencias culturales y simbólicas, entre las comunidades exiliadas y las de acogida. Proponemos una mirada que contemple las múltiples aristas en torno al exilio y, en este caso concreto, el impacto que una comunidad forzada a dejar su patria generó en el espacio de recepción

Palavras-chave: Exilio chileno, transnacional, Latin American Bureau.

\begin{abstract}
This article intent to contribute to a research lineabout exile as a transnational phenomenon. From the analysis of the Chilean exile in British lands as a result of the military coup that Salvador Allende demolished (1970-1973), we will investigate the marks that exile left among those who were based on activities of solidarity with Chile. In particular, we will focus on an editorial venture born in 1977 in London, the Latin American Bureau, because we think that it materializes cultural, symbolic transfers, etc., between exiled and host communities. We propose a point of view to contemplate multiples edges about exile, and in this specific case, the impact that a exilean community left in the reception space.
\end{abstract}

Keywords: Chilean exile, trasnational, Latin American Bureau 


\section{Introducción}

El 11 de setiembre de 1973 el calendario marca un hito fundamental, no sólo por la tragedia que sobrevendría en Chile sino, también, por las múltiples historias y reflexiones que generó el fin del gobierno de Salvador Allende Gossens (1970-1973). Con el bombardeo a la Casa de la Moneda se inició un régimen militar de 17 años (1973-1990) cuyas consecuencias económicas, sociales, políticas y culturales aún hoy no logran revertirse. Además de tratarse del derrocamiento de un presidente socialista elegido a través de las urnas, se interrumpió un proceso de estabilidad democrática de larga data -con limitaciones y falencias ${ }^{1}$-, con un sistema de partidos políticos que lo distinguió de los países de la región, sobre todo de otros países cono-sureños como Argentina y Brasil (GARRETÓN, 1993; ANGELL, 1974; ROUQUIÉ, 1981). Tal como expresan Simon Collier y Willian Sater en relación a la posibilidad de un golpe militar en Chile, hacia fines de la década del sesenta "los chilenos creían que eran inmunes a ese virus en particular" (COLLIER Y SATER, 1998: 281).

A la luz de los objetivos de este trabajo conviene detenerse para subrayar el impacto que el programa de Salvador Allende Gossens despertó en distintos ámbitos de la arena política internacional. Este tópico atraviesa nuestro abordaje ya que esa repercusión tuvo consecuencias en las características del exilio chileno en general y en los espacios de acogida del mismo. El programa de Allende gozó de una amplia

\footnotetext{
${ }^{1}$ Manuel Antonio Garretón considera que, a pesar de ciertos elementos favorables del sistema político chileno, éste no estaba libre de ciertas falencias como la baja participación electoral de la población hasta los años cincuenta, la incapacidad de construir gobiernos con una legitimidad mayoritaria y la debilidad de la sociedad civil frente al poder de los partidos políticos, entre otros (GARRETÓN, 1993). Asimismo, Carlos Huneeus se centra en cuestionar la idealización del régimen político chileno al destacar las prácticas abiertamente antidemocráticas existentes desde mediados de los años 40, como la denominada Ley Maldita, por la cual se proscribió de la participación electoral al Partido Comunista chileno entre 1948 y 1958. (HUNEEUS, 2009). Respecto del sistema electoral, desde los inicios del Siglo XIX hasta 1874 fue de tipo censitivo donde la situación patrimonial tenía un importante peso a la hora de ser candidato o elector. En 1874, por presión de sectores políticos liberales se sancionó una nueva ley electoral que amplió el derecho a voto a ciudadanos que sabían leer y escribir y con un ingreso justificado. Hacia fines del Siglo XIX se fueron eliminando los requisitos patrimoniales para el ejercicio de este derecho ciudadano, que hacia 1888 lo ejercían sólo un 3.5\%, entre otras razones, por no haberse inscripto para votar. En 1925, la nueva Constitución otorgó más poder al presidente sobre el parlamento y la elección era por votación directa. Las mujeres tuvieron que esperar hasta el año 1949 cuando se les reconoció por ley su derecho a voto para elecciones presidencias y parlamentarias. La obligatoriedad del voto se sancionó en 1962 para evitar la baja participación de la población en las elecciones y, en 1970, se redujo a los 18 años la edad mínima del votante y se eliminó el requisito de saber leer y escribir para poder ejercer el derecho a voto. Así, para las elecciones parlamentarias de 1973, se registró un aumento notable en la participación electoral de la población chilena (NAZER Y ROSEMBLIT, 2000).
} 
adhesión y generó enormes expectativas en sectores progresistas de Europa, principalmente en la parte Occidental. El triunfo electoral de un presidente que se declaraba marxista colocó a Chile en un lugar privilegiado e inédito que problematizó al mundo político. En su mensaje al Congreso, el 21 de mayo de 1971, Allende definió a su programa como el "segundo modelo de transición al socialismo" sin "dictadura del proletariado" (ARRATE Y ROJAS, 2003). La experiencia chilena abría la posibilidad histórica de conquistar el socialismo por la vía electoral, lo que implicaba una alternativa diferente a la adoptada por Cuba y por los países de Europa del Este. El fin de este proceso a través de la violencia generó no sólo un amplio rechazo sino, también, múltiples manifestaciones de solidaridad con el pueblo chileno. Asimismo, el último discurso de Allende difundido en vivo a través de Radio Magallanes desde La Moneda el mismo 11 de setiembre, las fotografías e imágenes televisadas del bombardeo, de asesinatos, de quema de libros, entre otras, produjo un impacto emocional que marcó la vida de muchos/as fuera de las fronteras chilenas. Tal como expresaron dos académicos británicos entrevistados "el golpe fue, sin duda, en todo lo que ha pasado en mi vida, el peor golpe, entre comillas, que yo he sufrido en mi vida política e, incluso, después no me ha pasada nada peor que el golpe de Chile, porque creo que todos nos dimos cuenta, probablemente, que era el comienzo del fin de todos estos sueños de los años setenta" (Martin, 2009) o "fue como la muerte súbita de un amigo" (LEHMANN, 2009).

A partir del golpe, las Fuerzas Armadas chilenas impusieron una dictadura institucional con una Junta de Gobierno y, simultáneamente, fuerte concentración del poder en la figura de Augusto Pinochet (ANSALDI, 2004; HUNEEUS, 2000). Entre las múltiples consecuencias de esta dictadura nos centraremos, tal como hemos señalado, en el exilio; proceso difícil de definir en un único sentido, por lo que creemos necesario dar cuenta de la complejidad de la categoría misma y presentar nuestra perspectiva en torno a la misma.

\section{El exilio como fenómeno transnacional}

Entre los/as estudiosos/as del exilio existe consenso acerca de la ambigüedad de este término para definir un fenómeno difícil de reducir a un único sentido (JOLY, 1996; REBOLLEDO, 2006; FRANCO, M; 2008). Tal como expresa Silvina Jensen, el exilio constituye un objeto de estudio móvil y poliédrico (JENSEN, 2011). Los variados 
motivos de una migración forzada, sumados a las múltiples formas de salida del país y a los diferentes status legales que los/as exiliados/as han recibido en distintos países de acogida, complejizan el análisis del exilio y los límites de las distintas categorías que dan cuenta del proceso.

La situación de exilio implica la violación de los Derechos Humanos (DDHH) contemplados en el Artículo 9 de la Declaración Universal (1948). "Nadie podrá ser arbitrariamente detenido, preso, ni desterrado" y en el Artículo 13: “1. Toda persona tiene derecho a circular libremente y a elegir su residencia en el territorio de un Estado. 2. Toda persona tiene derecho a salir de cualquier país, incluso del propio, y a regresar a su país" ${ }^{\text {. }}$. Estos artículos se complementan con el Artículo 14 que considera un derecho de los hombres la búsqueda de asilo en caso de persecución: “1. En caso de persecución, toda persona tiene derecho a buscar asilo, y a disfrutar de él, en cualquier país. 2. Este derecho no podrá ser invocado contra una acción judicial realmente originada por delitos comunes o por actos opuestos a los propósitos y principios de las Naciones Unidas (DECLARACIÓN UNIVERSAL DE LOS DERECHOS HUMANOS, 1948).

Ahora bien, cuando se utiliza el concepto de exilio en el terreno del análisis sociológico e histórico comienzan los problemas: la variación nacional de la definición jurídica de la situación de exilio; los límites de la categoría del refugiado estatutario según el Estatuto del Refugiado-Convención de Ginebra de 1951-; los problemas derivados de la determinación de las motivaciones subjetivas de los/as exiliados/as al momento de partir de su patria; las diferencias y límites entre migración política y migración económica y las diversas formas de salida del país aportan complejidad a la hora de conceptualizar. Las categorías sociológicas deben dar cuenta de una realidad que no está ordenada de acuerdo a las definiciones pautadas en el ámbito jurídico y de una diversidad de situaciones no siempre contemplada en figuras legales. Por cuestiones de espacio no podemos dar cuenta de estas figuras; sólo señalaremos, a partir del aporte de Pérez Barahona (2003) que, junto a la figura del refugiado estatutario, co-existe una variedad de "refugiados/as" no contemplada en dicha figura, como lo son los y las refugiados/as de facto (a-jurídicos), los refugiados en masa, los desplazados, quienes carecen del estatus legal aprobado en la Convención de Ginebra. Fanny Jedlikcki se suma a la crítica de la categoría de refugiado, advirtiendo sus limitaciones en tanto

\footnotetext{
2 Artículo 13, Declaración Universal de Derechos Humanos, proclamada y aprobada por Asamblea General de las Naciones Unidas el 10 de diciembre de 1948. Disponible en http://www.un.org/es/documents.
} 
elemento del orden internacional atrapado en la lógica de los asuntos de Estado (JEDLICKI, 2007).

En definitiva, nuestro posicionamiento se aleja de los términos jurídicos y adscribimos a una mirada amplia en torno al exilio, es decir incorporando el forzamiento a dejar la patria por razones socio-económicas que se desprenden de la política represiva impuesta, en este caso, por la dictadura militar chilena. Asimismo, atendiendo la multiplicidad de experiencias que una misma comunidad nacional vive en el exilio, adherimos al término exilios en lugar de su singular (REBOLLEDO, 2006; YANKELEVICH Y JENSEN, 2007) y, en el mismo sentido, podemos hablar de múltiples retornos a la patria.

En cuanto a las cifras de los exiliados/as de Chile a partir de 1973, existe una dificultad que se desprende precisamente de la ambigüedad conceptual. Carmen Norambuena (2000) destaca que la cifra ascendió a 408.000 chilenos y chilenas, otros autores afirman que cerca de un millón de personas dejaron el país durante la dictadura militar, a causa de la crisis política y sus consecuencias socioeconómicos (MONTUPIL, 1993). Lo cierto es que miles de chilenos/as salieron de su país -situación inédita hasta el momento para Chile ${ }^{3}$ - y conformaron una potente diáspora que luchó contra el régimen de Pinochet y dieron forma a núcleos de chilenidad (ARRATE, 1987), en varios casos sostenidos por el financiamiento internacional. "Localmente, el caso chileno se convirtió en una "causa célebre" para los europeos y encontró fuertes ecos en funcionarios públicos, parlamentarios, activistas partidarios, sindicalistas, asociaciones de Derechos Humanos, iglesias católicas y protestantes y federaciones estudiantiles" (SZNAJDER Y RONINGER, 2007:50).

Ahora bien, al abordar una situación exiliar concreta - exiliados/as en el Reino Unido y, particularmente, un programa de becas financiado por el gobierno laborista británico y administrado por el World University Service - United Kingdom, (WUS UK) 1974-1986 (BAYLE, 2010)- nuestra caja de herramientas teóricas se amplificó. El análisis de este programa sistemático de asistencia a académicos/as exiliados/as en

\footnotetext{
${ }^{3}$ Chile, hasta la década del setenta del siglo pasado, no había experimentado un proceso de exilio masivo tal como el que se dio como consecuencia del golpe militar. Desde las luchas por la Independencia se produjeron casos individuales de perseguidos políticos que salieron de Chile, tales como Bernardo O’Higgins, quien se exilió en Perú desde 1823 hasta su muerte en 1942; los opositores al gobierno de Carlos Ibáñez de Campo y el desplazamiento de los comunistas como consecuencia de la Ley de Defensa de la Democracia, conocida como Ley Maldita, sancionada en 1948 (presidencia González Videla) para proscribir la participación política del Partido Comunista (NORAMBUENA, 2000).
} 
tierras británicas nos condujo a poner la mirada en la sociedad de acogida y en las múltiples aristas que esto implicaba. Trabajamos las relaciones diplomáticas -históricas y a partir del golpe- entre Chile y el Reino Unido (BAYLE, 2017); los vínculos políticos, académicos, culturales entre estos dos países; la política británica en relación al refugio, su legislación, su política de acogida (JOLY, 1987, 1996; DIANA KAY,1987); el impacto del golpe militar en los sectores progresistas británicos (académicos, políticos, sindicales, etc.) y las trayectorias de vida de agentes vinculados a distintas instancias de solidaridad con el pueblo chileno y de oposición a la dictadura (BAYLE, 2012); entre muchas otras variables. Nuestro itinerario de investigación no sólo implicó un traslado a la tierra de recepción para buscar documentación y recoger testimonios, sino que fue mostrando la necesidad de redefinir el abordaje del exilio y comenzar a pensarlo como un fenómeno transnacional, donde dos comunidades nacionales, heterogéneas cada una de ellas en su interior (con diferencias sustanciales de clases, posiciones políticas distintas, etc.) construyeron redes que trascienden lo meramente instrumental. Tal como hemos señalado en otros trabajos (BAYLE, 2012) descubrimos que este vínculo tenía una historia que definió la política de acogida en el país receptor y que el movimiento de solidaridad que contribuyó a forjar impactó no sólo en los y las exiliados/as sino, también, en la trayectoria de militantes y académicos/as progresistas del Reino Unido; quienes adquirieron/acumularon un "saber hacer" que luego reconvirtieron en otros espacios. Nos referimos al capital militante entendido como una serie de aprendizajes y disposiciones que es incorporado en experiencias políticas colectivas y que puede ser reconvertido en distintos universos (MATONTI ET POUPEAU, 2004). El acercamiento, a través de metodología cualitativa, a agentes británicos/as condujo a pensar en que los/as chilenos/as exiliados/as en el Reino Unido simbolizaban algo especial para algunos/as británicos/as. Advertimos en sus relatos que ubicaron el bombardeo de La Moneda en una línea de continuidad que se remontaba a la lucha librada durante la República española. En consecuencia, se reactivaron los lemas libertarios, donde el lugar de Franco era ocupado en aquel momento por Pinochet, la Republica española estaba reencarnada en la Unidad Popular chilena y las otroras brigadas internacionales debían construirse en base a la solidaridad y la acogida a los y las exiliados/as.

En base a estas premisas, presentaremos un caso editorial que creemos materializa el impacto del exilio chileno en la intelectualidad británica y donde, aún hoy, pueden identificarse las marcas del exilio que se reactivan, por ejemplo, ante 
situaciones concretas como la crisis actual en Chile (octubre, 2019), en la defensa de los Derechos Humanos, entre otras situaciones. Se trata del programa Latin American Bureau (LAB) ideado por intelectuales y activistas a mediados de los años setenta como un espacio para promover la investigación y la publicación de textos sobre Derechos Humanos, desarrollo, educación y justicia en relación a América Latina. Quienes crearon y continúan este emprendimiento estuvieron estrechamente vinculados a la solidaridad con los y las chilenos/as y demás latinoamericanos/as en situación de exilio en los años setenta del siglo pasado. Con este estudio pretendemos contribuir a la producción de una línea de investigación en torno de las transferencias ocurridas en el exilio que, además de observar la relevancia de este fenómeno en la vida de los/as exiliados/as, indague en las reconversiones que genera en agentes del país receptor. Para la confección este artículo hemos contado con entrevistas en profundidad a académicos/as y militantes británicos/as, la mayoría de ellas realizadas en el Reino Unido para nuestra tesis doctoral (BAYLE, 2010). Asimismo, hemos analizado y sistematizado material de archivo de The National Archives (Londres) y catálogos del Latin American Bureau.

Antes de analizar el caso del LAB creemos necesario realizar una breve descripción del exilio chileno en tierras británicas y las distintas instancias de solidaridad generadas en ese espacio de acogida.

\section{El exilio chileno a partir de 1973 en el Reino Unido}

La dictadura militar chilena fue la responsable no sólo de la salida forzada de miles de chilenas y chilenos, sino de su particular itinerario, por la serie de disposiciones administrativas y decretos leyes dirigidos a los opositores políticos al régimen. Estos mecanismos formaron parte del proyecto represivo de este gobierno autoritario para neutralizar a agentes opositores, portadores/as de proyectos alternativos de cambio social (NORAMBUENA, 2000). En los primeros días del golpe, a través de los Bandos Militares, se publicaron listas de las personas que debían presentarse ante las autoridades militares. La voluntad manifiesta, con fundamento en la Doctrina de Seguridad Nacional, era "limpiar al país de los enemigos de la patria, de aquellos ligados al comunismo internacional, para poder refundarla" (REBOLLEDO, 2006:19). Esto provocó un temor generalizado y, en consecuencia, el pedido de asilo 
(ORELLANA, 1981; LASTRA Y PEÑALOZA PALMA, 2016) o la salida clandestina, en especial hacia países vecinos como Perú y Argentina (PAREDES, 2007), fueron las primeras formas que adquirió el exilio chileno.

Europa recibió a los y las chilenos/as desde el mismo mes de septiembre de 1973. Ya adelantamos el fuerte impacto que el golpe militar tuvo en distintos ámbitos, sin embargo, no todos los países tuvieron los mismos mecanismos de recepción; incluso no todos abrieron las puertas de sus misiones diplomáticas acreditadas en Santiago. Las diferencias estuvieron marcadas por el vínculo previo con Chile, el color del gobierno de turno en los países de acogida, la política de inmigración y, posiblemente, por la forma particular-tradicional en que cada Estado manejaba sus relaciones exteriores, entre otras variables. Más allá de las diferencias por países, Europa constituyó un lugar de protección temporaria, para mantener la vida de los/as exiliados/as entre un paréntesis que se extendió por muchos años, para ser, luego de casi tres décadas de concluido el régimen militar, un lugar de residencia permanente para muchos/as chilenos/as (BOLZMAN, 2006).

En relación al Reino Unido, es necesario destacar que, al momento del golpe, el país era gobernado por el Primer Ministro Edward Heath (1970-1974), del Partido Conservador. Las mayores simpatías hacia el gobierno de Allende y el rechazo al golpe militar en el campo político provenían del Partido Laborista -en la oposición hacia 1973- y de los sectores sindicales y otras organizaciones políticas ligadas al pensamiento de izquierda. A pesar de las múltiples presiones de estos sectores, de chilenos/as residentes y de ciertos sectores del campo académico, el gobierno de Edward Heath reconoció al gobierno militar el 22 de septiembre de 1973 ${ }^{4}$. Los conservadores alegaron que el criterio de reconocimiento de un nuevo gobierno se basaba en que éste tuviese control sobre todo el territorio y no en el perfil ideológico del gobierno. Lo cierto es que el acto de reconocimiento generó, al igual que en otros países, un fuerte rechazo por parte de los sectores comprometidos con el pueblo chileno afectado por el golpe, que pedían, además del rompimiento de relaciones diplomáticas, el boicot económico al gobierno chileno (BAYLE, 2017).

\footnotetext{
4 Según dichos confidenciales del Vice-almirante Oscar Buzeta, al momento de pronunciar el reconocimiento del gobierno de Pinochet, el Ministro de Relaciones Exteriores, Sir Alec Douglas Homes, "puso especial énfasis en que el acto de reconocimiento de un régimen no implicaba en manera alguna aprobación del mismo en términos morales o ideológicos”. Oficio Confidencial $N^{\circ} 30$, DRI. Del ViceAlmirante, Oscar Buzeta al Ministro de Relaciones Exteriores, Londres 5 de octubre de 1973. Archivo Documental Ministerio de Relaciones Exteriores de Chile. Carpeta Gran Bretaña
} 
Respecto de la posibilidad de dar asilo diplomático en la Embajada Británica en Chile, el Secretario de Estado para las Relaciones Exteriores, Julian Amery, explicó que la política oficial al respecto consistía en que las Embajadas no podían ser lugar de asilo, ya que su función era mantener la relación entre dos gobiernos, por lo que no podían "por definición” resguardar a miembros de la oposición al gobierno".

A partir de las elecciones generales del 28 de febrero de 1974 y con el triunfo del Partido Laborista, la situación cambió en relación al exilio chileno. Accedió al cargo de Primer Ministro Harold Wilson (1974-1979) representando a un partido que, según Walter Laqueur (1994), se había desplazado constantemente hacia la izquierda durante la década del 60. Un hecho de suma importancia para la oposición a Pinochet fue la fuerte presión del movimiento de trabajadores sobre el gobierno de Wilson en este período. Este sector, que tenía entre sus líderes a Jack Jones -un ex combatiente contra el fascismo en España-, presionó constantemente al gobierno para extremar sus medidas contra el régimen militar chileno. En marzo de 1974 el nuevo Secretario de Estado para las Relaciones Exteriores, James Callagham (1974-1976), pronunció en la Cámara de los Comunes el deseo oficial de la restauración de la democracia en Chile y dejó en claro que el gobierno permitiría la entrada al país de exiliados/as chilenos/as. Respecto de aceptar a no nacionales en la Embajada del Reino Unido en Chile en busca de asilo, la situación no se revirtió. El gobierno laborista mantuvo las puertas cerradas de su Embajada apoyándose, entre otras razones, en que el gobierno militar chileno no hacía entrega de salvoconductos que permitiesen la salida de perseguidos/as fuera del país. Asimismo, esta apertura, que implicó la llegada de cerca de 3000 chilenas y chilenos a territorio británico ${ }^{6}$, no se correspondió con una modificación radical en los procedimientos para el otorgamiento de visas y en un aceleramiento de los tiempos burocráticos. Menos aún, con una adecuada política gubernamental de acogida (Joly, 1987). El gobierno dejó en manos de distintas organizaciones civiles la responsabilidad de la recepción y acogida. Si bien, por razones de espacio, no podemos profundizar en

\footnotetext{
${ }^{5}$ Oficio Confidencial No ${ }^{\circ}$. Asesoría Política. Del Embajador Kaaren Olsen al Ministro de Relaciones Exteriores de Chile, Londres 29 de noviembre de 1973. Archivo Documental Ministerio de Relaciones Exteriores de Chile. Carpeta Gran Bretaña.

${ }^{6}$ Los/as chilenos/as obtuvieron la figura legal de Refugiado o Permiso excepcional para permanecer.
} 
las distintas instancias de solidaridad con el pueblo chileno y de oposición a la dictadura militar, ofrecemos una aproximación a las mismas ${ }^{7}$.

\section{Instancias británicas de solidaridad con el pueblo chileno en el exilio}

A partir del golpe de 1973 en Chile, comenzaron a formarse en el Reino Unido distintas instancias de oposición a Pinochet; de solidaridad con el pueblo chileno; de presión al gobierno británico, primero para permitir la entrada de exiliados/as y, luego, para asegurar la acogida y asistencia a exiliados/as y para bregar por la defensa de los Derechos Humanos. Entre estas organizaciones es de suma importancia destacar el trabajo del World Universtiy Service United Kingdom (WUS UK). Esta Organización No Gubernamental administró un programa de becas para 900 refugiados/as chilenos/as -con distintos grados de capital académico- en el Reino Unido a partir de 1974. Su antecedente inmediato fue Academics for Chile (AFC), una organización informal creada a días del golpe por académicos británicos: Alan Angell de la Universidad de Oxford era su Secretario Ejecutivo, Cristian Anglade de la Universidad de Essex, Presidente y David Rock de la Universidad de Cambridge, Tesorero. Se sumaron prestigiosos/as intelectuales como Ann Zammit, Emanuel de Kadt, Duddley Seers (quien tuvo un rol fundamental en relación a los fondos), entre otros/as. Con el triunfo de los laboristas en 1974, ACF recurrió al WUS UK por su experiencia en la asistencia a académicos en situación de refugio y gracias a la canalización de fondos destinados a la "ayuda para el desarrollo", provenientes del Overseas Development Ministry bajo el mando de Judith Hart, el WUS UK logró administrar y ejecutar el Chilean Refugee Scholarship Programme (CRSP) que incluyó, además de becas, una política de reubicación y retorno a Chile (BAYLE, 2010; BAYLE, 2013). No podemos explayarnos en esta organización, pero sí señalaremos que el WUS UK formó parte de la estructura del WUS Internacional, organización que hacia fines de los años setenta y durante casi dos décadas experimentó un proceso de latinoamericanización que incluyó la conformación de 16 comité nacionales en América Latina. Sus tópicos estuvieron vinculados a la defensa de los DDHH, la educación, la asistencia a refugiados/as y la lucha por la democratización (BAYLE Y NAVARRO, 2018). En el caso del WUS UK

\footnotetext{
${ }^{7}$ Este tópico ha sido trabajado en mayor profundidad en Bayle; 2010 y 2012. Este apartado remite a estos trabajos.
} 
debemos mencionar que esta organización para el programa de becas para chilenos/as trabajó estrechamente con el Consejo Latinoamericano de Ciencias Sociales, CLACSO (BAYLE, 2008); con la Facultad Latinoamericana de Ciencias Sociales, FLACSO (Chile) y con organizaciones de derechos humanos y religiosas (Vicaría de la Solidaridad, Chile; Fundación de Ayuda Social de las Iglesias Cristianas, FASIC, entre otras). Alan Phillips, Secretario Ejecutivo del WUK UK, fue un agente clave para la puesta en marcha del programa de becas, pues supo construir una buena relación con agentes del campo político, funcionarios del Estado y con miembros del campo académico. El trabajo de esta organización involucró a muchos/as británicos/as, como John King, Gerard Martin, Liz Fraser, Pauline Martin, Philip Rudge, Marylin Thompson, Sebastian Brett, entre otros/as, con distintas responsabilidades y grados de compromiso.

Además del WUS UK existieron tres organizaciones británicas de solidaridad con el exilio chileno que actuaron en forma coordinada, pero manteniendo una identidad propia. Se trató del Joint Working Group For Chilean Refugee (JWG) -un consorcio formado para la recepción-, el Chile Committee for Human Right (CHCHR) -un comité de defensa de los DDHH - y la Chile Solidarity Campaign (CHSC) -con un perfil eminentemente político de presión y de solidaridad con el exilio chileno. Estas fueron tres manifestaciones de ayuda que, si bien se basaron en una tradición en actividades de caridad y voluntariados propia de los británicos como afirma Joly (1996), pueden explicarse por la transcendencia de Chile en los años setenta.

El Joint Working Group For Chilean Refugee (JWG) comenzó a funcionar a mediados de 1974 y estuvo conformado por representantes de distintas organizaciones no gubernamentales. Su co-coordinador fue Gordon Hutchison (1947) quien había estado en Chile durante la experiencia de la Unidad Popular, cursó Sociología en la Universidad de Concepción y estuvo vinculado a actividades de voluntariado en el desierto de Atacama. El objetivo de JWG era propiciar una óptima recepción y esto implicaba una visible lucha en el campo de poder estatal para agilizar la entrega de visas y recursos financieros; al mismo tiempo, coordinaba sus actividades con la CHSC y el CHHRC para denunciar al gobierno chileno por la violación de los DDHH y para que el gobierno británico se posicionara en contra de la dictadura de Pinochet. Es de destacar la fuerte participación de voluntarios/as en distintas tareas coordinadas por el JWG, 
derivada de su inestabilidad financiera ${ }^{8}$ y por el fuerte compromiso hacia el pueblo chileno, sobre todo en comunidades donde el Partido Laborista y el movimiento sindical tenían incidencia. La ayuda voluntaria -OXFAM, sindicatos, entre otroscomplementaba la ayuda estatal que era canalizada a través del Departamento de Empleo, el Departamento de Salud y Seguridad Social y la ayuda de las autoridades locales y Consejos de Relaciones con la Comunidad de distintas comunas (Joint Working Group for Refugees, 1975).

Por su parte, el Chile Committee for Human Rights (CHCHR) se creó en enero de 1974 con el eje de su trabajo en la denuncia por la violación de los DDHH y en la asistencia humanitaria a víctimas de la política represiva. En ese marco, se sumó a la lucha política por la aceptación de chilenos/as en el Reino Unido. Este comité estuvo liderado en sus inicios, en términos ejecutivos, por una británica con una experiencia de vida en Chile, Wendy Tyndale, pues antes del golpe del 1973 trabajó en la sede de Talca de la Pontificia Universidad Católica de Chile. Tyndale compartía su secretariado con Susan Carstairs, también fuertemente comprometida con la "causa chilena". Asimismo, esta organización fue presidida por la bailarina y coreógrafa británica Joan Jara, viuda de Víctor Jara, quien ejerció un importante papel en promocionar la cultura chilena en el Reino Unido. El $\mathrm{CHCHR}^{9}$ comenzó a trabajar sin fondos fijos, sólo con donaciones de particulares. Al poco tiempo recibió el soporte de las iglesias cristianas, quienes financiaron sus actividades y tenía el patrocinio de miembros de Cámara de Lores (Chile Committe for Human Rights, London: 1982)

Finalmente, debemos sumar la Chile Solidarity Campaign (CHSC) con un rol estrictamente político. Se estableció sobre la base de otro movimiento, el Movement for Colonial Freedom, a partir del cual el Partido Laborista inglés, el Partido Comunista y los sindicatos británicos crearon campañas de solidaridad con Vietnam y de lucha contra el apartheid, entre otras. La CHSC asumió un papel fundamental en la persistente denuncia a la dictadura chilena y en la búsqueda de adhesiones hacia el exilio. Se trató de una de las tantas expresiones de solidaridad internacional del movimiento sindical, con fuerte participación de Transport and General Workers Union

\footnotetext{
${ }^{8}$ Los fondos oficiales, finalmente recibidos, provenían de un departamento del Home Office encargado de financiar actividades voluntarias, el Voluntary Service Unit.

${ }^{9}$ Este consorcio estaba compuesto voluntarios/as y personal permanente de: Chile Relief Fund, CHSC, WUS UK, JWG, Chirstian Aid, Catholic Fund for Overseas Development (CAFOD), los Cuáqueros, ONU, War on Want, el Grupo Chileno de Salud y agentes individuales.
} 
(TGWU), por esa época el sindicato con mayor cantidad de afiliados en el país ${ }^{10}$. El patrocinio y financiamiento provenía de los sindicatos y de los partidos políticos representados en la campaña (TRADE UNION CONFERENCE REPORT, 1975; GATEHOUSE, 2009). El primer Secretario Ejecutivo de CHSC fue Steve Hart, hijo de Judith Hart -Ministra de Overseas Development Ministry a partir de 1974- quien tuvo un rol central en la solidaridad con el exilio chileno. En sus orígenes la CHSC funcionó en las oficinas de Liberation, otra organización ligada los movimientos por la liberación colonial. La campaña de solidaridad tuvo un representante que logró dinamizarla, Mike Gatehouse, que se incorporó como co-secretario junto a Hart y luego junto a Colin Henfrey. Al igual que Hutchison y Tyndale, Gatehouse vivió en Chile durante la experiencia de la Unidad Popular y al momento del golpe permanecía en ese país, fuertemente comprometido con los procesos de cambios propuestos por Allende. Estuvo preso en el Estadio Nacional y al regresar al Reino Unido dedicó varios años de su vida a la Campaña.

La solidaridad y las acciones de denuncia no fueron sólo expresión de la dirigencia sindical -aunque cumplió un rol fundamental en promocionarla-, sino que se manifestó, además, en múltiples acciones individuales. La oposición al comercio con Chile que trabajadores locales presentaron para boicotear al gobierno de Pinochet fue sumamente dura.

Estas organizaciones establecieron alianzas coyunturales con activistas, agencias intergubernamentales y otras ONGs, para conformar advocacy networks, en términos de Keck y Sikkink (1998). Estas alianzas incluyeron tanto a organizaciones chilenas Vicaría de la Solidaridad, Fundación de Ayuda Social de las Iglesias Cristianas (FASIC), Comité de Cooperación para la Paz (COPACHI), Comité Exterior Mapuche, la Agrupación de Familiares de Detenidos Desaparecidos y con el Comité por el Derecho de Vivir en la Patria, entre otras- como a instituciones internacionales, tales como Cruz Roja, Alto Comisionado de las Naciones Unidas para los Refugiados (ACNUR), Comité Intergubernamental para las Migraciones Europeas (CIME) o Amnesty Internacional.

Es necesario destacar que los y las chilenas se incorporaron y participaron en estas experiencias de manera voluntaria, fueron consultados/as pero no dirigieron ni

\footnotetext{
${ }^{10}$ El otro sindicato representado en la campaña fue el sindicato de trabajadores de la ingeniería, el Amalgamated Engineering and Electrical Union (AEEU).
} 
ocuparon espacios de liderazgos en estas organizaciones. En paralelo, existieron en el Reino Unido células de movimientos y partidos políticos chilenos, pero mantuvieron su autonomía respecto de las organizaciones británicas.

Ahora bien, en estas instancias de solidaridad con el exilio chileno, se incorporaron cientos de británicos/as con distintos niveles de compromiso. Un primer acercamiento etnográfico nos mostró que, si bien varios/as tenían experiencia de voluntariados previo a su contacto con Chile, fue a partir del contacto con el pueblo chileno en el exilio y del involucramiento en la causa chilena que redefinieron sus trayectorias laborales y acumularon una experiencia política inédita en sus vidas. Gracias a esta experiencia en militancia y solidaridad, acumularon saberes -capital militante en términos de Poupeau y Matonti (2004)- que luego aplicaron en otras causas. Los distintos agentes que trabajaron por Chile en el Reino Unido entrevistados/as en ese país- continuaron trabajando para organizaciones o proyectos vinculados a la promoción del desarrollo, la asistencia a refugiados y los DDHH en distintas áreas del mundo hasta la actualidad.

Para este grupo el compromiso con los procesos políticos que ocurrieron contemporáneamente en Centroamérica en los años ochenta fue el paso siguiente luego del caso chileno. De modo particular, dos países de América Central "se destacaron por situaciones de violencia generalizada: Nicaragua y El Salvador...Tres elementos estaban en la base de la convulsión social de las décadas de 1960 y 1970: la demanda de democracia política, la reivindicación de justicia social y el reclamo por la tierra" (ANSALDI Y GIORDANO, 2012: 327). Estas demandas y luchas hicieron eco en sectores progresistas europeos y de otros países latinoamericanos. Así, un número importante de británicos/as comprometidos/as con Chile erigieron a Centroamérica como eje de preocupación. Según sus testimonios, la lucha política en su propio país no generaba ningún tipo de expectativa.

Hasta aquí hemos analizado de qué manera la experiencia de militancia y solidaridad con el pueblo chileno exiliado en el Reino Unido generó cambios y disposiciones en los británicos comprometidos con este proceso. Esta militancia implicó la acumulación de nuevos saberes y de capital militante entendido como un "saber hacer", que fue incorporado en experiencias políticas colectivas y que pudo ser reconvertido en distintos universos (MATONTI ET POUPEAU, 2004). Hemos identificado -y esbozado sintéticamente- las marcas del exilio chileno en las trayectorias quienes se comprometieron con la causa chilena. En adelante nos centraremos en el 
Latin American Bureau, LAB, porque, creemos, materializa aún hoy -octubre de 2019el impacto que generó el caso chileno en las tierras de acogida.

\section{El Latin American Bureau}

El LAB es un emprendimiento editorial nacido en Londres a mediados de los años setenta. Múltiples causas se concentraron para dar forma a este proyecto cultural; entre ellas, el impacto en un grupo de británicos/as de la causa chilena exportada a la arena internacional. El LAB fue creado por intelectuales y activistas como un espacio para promover la investigación y la publicación de textos sobre Derechos Humanos, desarrollo, educación, justicia, en relación a América Latina. Los creadores de este emprendimiento estuvieron estrechamente vinculados a esta región con anterioridad a la llegada del exilio chileno a tierras británicas, pero la gran mayoría de sus colaboradores/as se sumó a esta iniciativa a partir de su experiencia en actividades de solidaridad con el exilio chileno. Julian Filochowski y Hugh O’Shaughnessy, dos de los iniciadores de este proyecto, tenían ya -hacia mediados de los años setenta- un fuerte compromiso con América Latina. Filochowski, vinculado a organizaciones cristianas, al terminar sus estudios universitarios en Economía en la Universidad de Cambridge, postuló para realizar trabajo voluntario en algún país en desarrollo. Fue destinado a Belice en 1969, a través del Instituto Católico de Relaciones Internacionales (ICRI) que, por entonces, tenía un programa de voluntariado en el exterior. A partir de allí, se trasladó a Honduras y luego a Guatemala. Fue nombrado co-coordinador del programa de voluntarios británicos en Centroamérica y allí tomó contacto con problemáticas centroamericanas que lo afectaron emocionalmente. Entabló fuertes vínculos con sectores progresistas de la Iglesia Católica, como el Monseñor Oscar Romero, arzobispo de San Salvador, ícono de la defensa de los DDHH en su país. Romero fue asesinado en 1980, situación que ha impactado fuertemente en la trayectoria de Filochowski ${ }^{11}$.

Hacia 1973, Filochowski regresó a Londres y fue designado a cargo del programa de Educación para América Latina, donde las variables a tener en cuenta según su propio testimonio- eran pobreza, desarrollo, dependencia y las relaciones con los sectores más progresistas de la Iglesia Católica de la región. Así, estableció vínculos

\footnotetext{
${ }^{11}$ Filochowski dirige la fundación "The Archbishop Romero Trust" encargada de promover la obra de Romero y apoyar actividades vinculadas a la defensa de los DDHH en América Latina.
} 
con el obispo Hélder Cámara en Brasil, el Cardenal Raúl Henríquez Silva en Chile y sacerdotes jesuitas en Centroamérica (FILOCHOWSKI, 2013)

Por su parte, Hugh O’Shaughnessy era corresponsal de la Agencia de Noticias Inter Press Service y del Financial Times -entre otros- en América Latina. Hacia fines de los años sesenta llegó a Chile y entabló una relación de amistad con Salvador Allende. Estuvo vinculado a organizaciones católicas y formó parte del comité ejecutivo del Instituto Católico de Relaciones Internacionales (ICRI). Luego del golpe militar y ya en el Reino Unido estuvo fuertemente comprometido con distintas acciones de solidaridad hacia el exilio chileno y de denuncia de las violaciones de los DDHH. (O’SHAUGHNESSY, 2009-2013)

Tanto Filochowski como O’Shaughnessy estuvieron vinculados al Partido Laborista británico en los años setenta y se sintieron movilizados en la lucha contra la dictadura militar de Pinochet. Desde el ICRI publicaban folletos o boletines sobre la situación de los DDHH en América Latina (Chile y Centroamérica principalmente). Esta organización es una entidad de caridad y por cuestiones legales no puede ejercer públicamente actividades políticas. Fue así que decidieron crear un proyecto editorial por fuera del Instituto para evitar condicionamientos. Nació de este modo el LAB, al amparo del ICRI, pero con autonomía editorial.

Su primera publicación de importancia fue Violence and Fraud in El Salvador: a report on current political events in El Salvador, en 1977, que recuperó testimonios de salvadoreños exiliados en Londres y reportes de prensa sobre la situación en este país centroamericano. Le siguieron: British and Latin America: an annual review of British Latin American relations, en 1978; Nicaragua: Dictarship and Revolution a cargo de J. Karmali, en 1979; Bolivia: Coup D'etat, de James Dunkerley, en 1980; Brazil: state and struggle, de Bernardo Kucinski, en 1982; Under the eagle, de Jenny Pearce; The great tin crash: Bolivia and the world tin market, escrito por John Crabtree, Gavan Duffy y Jenny Pearce, en 1986; Green gold: bananas and dependency in the Eastern Caribbean, de Bob Thomson, en 1987; Fight for the Forest, de Chico Mendez, en 1989; Panama: made in the USA, de John Weeks and Phil Gunson, en 1991, Faces of Latin American, de Duncan Green y Sue Brandon; entre otros. Muchas de otras publicaciones son contribuciones colectivas por lo cual no se identificaron los autores individuales.

El listado de libros es más amplio, pero en términos generales, nuclea temáticas sobre la violación de los DDHH en América Latina, el medio ambiente, el peso de las multinacionales en las economías regionales, la penetración norteamericana en el 
continente, con marcados tonos anti-imperialistas. Este trabajo de edición de libros se combinó con un trabajo de archivo documental, pues su fuerte vínculo con activistas y movimientos en defensa de los DDHH le permitió acumular información y documentos y poner a disposición en su Centro de documentación.

LAB contó con el financiamiento de distintas ONGs como OXFAM, Cristian AID, CAFOD, War or Want -todas estas vinculadas a la filantropía católica ${ }^{12}$ - y otros aportes personales. A pesar de estos fondos, la venta de sus productos editoriales se torna necesaria para la sobrevivencia del espacio.

En sus años fundacionales, el LAB estuvo fuertemente ligado a actividades de solidaridad con el exilio chileno y demás latinoamericanos. Trabajó estrechamente con el CHCHR y, de hecho, compartieron el mismo edificio. Es posible afirmar que aglutinó a sectores progresistas de la intelectualidad británica, con fuertes compromisos con América Latina y con una posición crítica respecto del papel de los países centrales en el devenir de los países en desarrollo. Sus promotores iniciales dejaron lugar a otros agentes y continuaron trabajando en organizaciones de promoción del desarrollo de países africanos y americanos. Continuaron ligados a la lucha por la defensa de los DDHH en distintos países de América Latina y en procesos de fortalecimiento de la democracia.

Esta experiencia ha continuado por más de cuarenta años en Londres, ha publicado cerca de 200 libros y, en varias ocasiones, ha co-publicado con editoriales de América Latina -Tercer Mundo, Siglo XXI, Editorial El Ancora-, de Estados Unidos Monthly Review, Temple University Press, Texas University Press-, del Caribe -Ian Randle- y de Europa -Lateinamerika Nachrichten-. Hacia mediados del 2000 tuvo problemas para publicaren papel por falta de fondos y en la actualidad ha revitalizado su proyecto bajo el formato digital. Desde el 2007 la era digital le ha permitido al espacio diversificar su comunicación y en actualidad combina noticias coyunturales sobre América Latina junto con publicaciones de libros producto de investigaciones. En el año 2015 LAB se asoció con Practical Action Publishing con el objetivo de fortalecer la

\footnotetext{
${ }^{12} \mathrm{Si}$ bien trasciende los objetivos de este trabajo, creemos que un análisis más detallado del LAB debe incluir referencias sobre la filantropía católica en el Reino Unido, su autonomía en relación a los partidos políticos locales y su rol en tanto financiadora de proyectos afines a la defensa de los Derechos Humanos, entre otros tópicos. De igual modo, sería de vital importancia incluir en la investigación a otros proyectos similares en otras latitudes, tales como North American Congress on Latin America (NACLA), creada en 1967; Washington Office on Latin America (WOLA), en 1966 y Council of Hemispheric Affairs (COHA), nacida en 1975 , todas en territorio norteamericano.
} 
edición de libros. Entre los productos recientes, fruto de esta asociación, podemos nombrar Voices of Latin American, social movements and the new activism, editado por Tom Gatehouse (2019) y que implicó no sólo un trabajo de investigación del editor por América Latina, sino también la colaboración de investigadores/as de la región y el testimonio de múltiples y variados/as activistas locales.

Es necesario advertir que en su sitio web las noticias sobre la situación chilena han ocupado, desde octubre del 2019, un lugar de importancia, con aportes de académicos y militantes de ese país, además de los textos de integrantes del LAB. También, es visible la preocupación por los movimientos ambientalistas y de género, por la situación en Bolivia, Ecuador, Brasil - con fuertes críticas a Jair Bolsonaro- entre otros tópicos.

Entre los/as actuales editores/as del LAB se encuentra Mike Gatehouse, quien, como ya hemos resaltado, cumplió un rol fundamental dinamizando la Chile Solidarity Campaign, y, actualmente, ejerce un papel central en el LAB.

Nuestro primer acercamiento a las distintas publicaciones y a sus autores/as nos permite observar que este espacio aglutina, por lado, a académicos/as con trayectorias consolidadas en sus campos disciplinares, portadores de prestigio académico producto de su capital académico acumulado, sobre todo en el área de los Latin American Studies. Este espacio les permite una escritura comprometida políticamente, alejada del corset de las prácticas evaluativas de los circuitos mainstream. Por otro lado, el espacio convoca a periodistas para la realización de investigaciones con profundidad, situación no siempre posible en sus ámbitos de ejercicio profesional. Finalmente, LAB integra a su red a jóvenes de distintos puntos del continente americano, no sólo británicos/as, comprometidos/as con distintos procesos políticos y resistencia (sindical, ambiental, política, social, contra la violencia de género) en la región, donde publican notas de opinión y trabajos de investigación.

\section{Palabras finales}

En este trabajo hemos abordado, en primera instancia, nuestra perspectiva en torno al exilio, en tanto fenómeno transnacional. Nos propusimos mostrar de qué manera el exilio afecta no sólo a los y las exiliados/a sino, también, a quienes los reciben en distintas latitudes. La historia de la recepción está atravesada por vínculos 
previos -que no han podido ser desarrollados en este trabajo por cuestiones de espacio-; por elementos simbólicos y políticos -entre otros-, que definen cada situación de acogida. Hubo una pregunta que orientó nuestros estudios previos sobre la recepción del exilio chileno en tierras británicas: ¿qué llevaban los y las chilenos/as en sus valijas? Pues bien, el acercamiento a agentes británicos nos condujo a pensar que quienes venían de Chile perseguidos/as por los militares simbolizaban algo especial para algunos/as británicos/as. Los y las chilenos/as portaban historias de militancia, compromiso político y, tal como expresó un activista británico, Chile hacia inicios de los años setenta "prometía una sociedad igualitaria. En el fondo, para nosotros, los ingleses, era una manera de conseguir en otro lado lo que nunca íbamos a conseguir en Inglaterra" (COAD, 2008).

En segundo término, nos abocamos al caso del exilio chileno en el Reino Unido, brindando un panorama general de su política de acogida, de las organizaciones a cargo de la misma y de las instancias de solidaridad con el pueblo chileno. Enfatizamos en el impacto que generó para un grupo de británicos/as su involucramiento en la causa chilena. Brindamos elementos que nos permiten afirmar que luego de su paso por las instancias de solidaridad con exiliados/as incorporaron un saber hacer, es decir desarrollaron un conjunto de disposiciones que luego reconvirtieron en otros espacios vinculados a los Derechos Humanos, al tópico del desarrollo, la lucha por la democracia, entre otros.

Seguidamente abordamos una iniciativa editorial británica que hasta la fecha reúne a intelectuales, periodistas, activistas y académicos/as comprometidos con América Latina. Quienes iniciaron este proyecto y muchos/as de quienes lo continúan militaron, desde distintos espacios, contra la dictadura militar en Chile y en solidaridad con los/as exiliados/as de ese país y, luego, de otros países latinoamericanos. También se involucraron con los procesos políticos ocurridos en Centroamérica a fines de los años setenta. Para muchos de ellos/as, la causa chilena fue el despertar al mundo de la militancia, canalizada a través de distintas ONGs, partidos políticos, organizaciones religiosas, entre otras.

A esto se suman otros elementos explicativos: este grupo de británicos/as propulsor del proyecto del LAB, en términos generales, pertenece a una franja etaria que realizó sus estudios universitarios en los años sesenta. En ese período, se vivieron procesos de radicalización política manifestada en la Campaña por el Desarme Nuclear, la lucha contra el apartheid y la guerra de Vietnam. En estas instancias, se puso en duda 
el papel del Reino Unido en el mundo y su responsabilidad política y moral por el estado de los países en desarrollo.

Volviendo al tópico del exilio en tanto fenómeno transnacional y, en nuestro afán de hacer visibles las marcas del exilio chileno en las tierras de acogida, queremos cerrar este artículo con un caso que creemos ilustra esta perspectiva. El 11 de setiembre de 2019 se cumplió un nuevo aniversario del golpe militar que derrocó a Salvador Allende en 1973. Ese día el LAB invitó a sus lectores/as a ver gratuitamente a través de su página web el documental "No pasarán" (2018). Este documental fue realizado por el director chileno-belga Felipe Bustos Sierra y registra la lucha de los obreros de los talleres de la Rolls-Royce en East Kilbride, Escocia, que durante muchos años se rehusaron a reparar los motores que la Fuerza Aérea chilena tenía en esa fábrica. Este boicot a la dictadura chilena generó cruces diplomáticos y políticos y expresó la reactualización en las gargantas de trabajadores escoceses, del No pasarán que la Pasionaria ${ }^{13}$ acuñó en 1936 contra los franquistas.

En definitiva, creemos que aún hoy podemos observar marcas de una historia que transcurrió hace años y que puso en contacto a dos comunidades más allá del océano que las separa. Hoy esas memorias de la resistencia y la lucha se actualizan frente al fuerte rechazo que la sociedad chilena está haciendo a las políticas neoliberales que se implementaron a partir de ese trágico 11 de setiembre de 1973.

\section{Fuentes y documentos}

ASAMBLEA GENERAL DE LAS NACIONES UNIDAS (1948). Declaración Universal de los Derechos Humanos. París, Resolución 217. Disponible en http://www.un.org/es/documents. Consultada: abril 2010.

CALLAGHMAN, James. Speech, House of Commons (27 de marzo de 1974). London, The National Archives.

CHILE COMMITTE FOR HUMAN RIGHTS (1982) London, mimeo.

JOINT WORKING GROUP FOR REFUGEES FROM CHILE IN BRITAIN (1975) Refugees from Chile: Joint Working Group Interim Report, London.

LATIN AMERICAN BUREAU, https://lab.org.uk/.

TRADE UNION CONFERENCE REPORT (1975) Chile and the British Labour Movement, London.

Oficio Confidencial $N^{\circ}$ 30, DRI. Del Vice-Almirante, Oscar Buzeta al Ministro de Relaciones Exteriores, Londres 5 de octubre de 1973. Archivo Documental Ministerio de Relaciones Exteriores de Chile. Carpeta Gran Bretaña.

\footnotetext{
${ }^{13}$ Dolores Ibárruri, la Pasionaria (1895-1989) fue Secretaria General del Partido Comunista de España y ferviente luchadora por la República y por la democracia.
} 
Oficio Confidencial No 50. Asesoría Política. Del Embajador Kaaren Olsen al Ministro de Relaciones Exteriores de Chile, Londres 29 de noviembre de 1973. Archivo Documental Ministerio de Relaciones Exteriores de Chile. Carpeta Gran Bretaña.

\section{Referencias bibliográficas}

ANGELL, Alan (1974). Partidos políticos y movimientos obrero en Chile.México: Ediciones Era.

ANSALDI, Waldo (2004) Matriuskas del terror. En PUCCIARELLI, Alfredo R. (Coord.). Empresarios, tecnócratas y militares. La trama corporativa de la última dictadura, Buenos Aires: Siglo Veintiuno Editores, pp. 27-49.

y GIORDANO, Verónica (2012). América Latina. La construcción del orden, Tomo II. Buenos Aires: Ariel.

ARRATE, Jorge y ROJAS, Eduardo (2003). Memoria de la Izquierda Chilena, Tomo II (1970-2000). Santiago de Chile: Javier Vergara Editor.

BAYLE, Paola (2008) Emergencia Académica en el Cono Sur. El programa de reubicación de Cientistas Sociales. Íconos, Revista de Ciencias Sociales. Ecuador, n. 30, pp. 51-53, enero.

- (2010) La diáspora de una población calificada: el exilio académico chileno en el Reino Unido. Tesis (Doctorado en Ciencias Sociales). Universidad Nacional de Cuyo, Mendoza, Argentina.

(2012) Los rubios. El compromiso británico hacia a las víctimas de la dictadura militar chilena (1973-1990). Sociedad hoy. Concepción, n. 22, pp. 77-93, primer semestre.

. (2013) Back Home: the World University Service UK return programme for Chilean academic exiles. En BEIGEL, Fernanda (Ed.). The politics of academic autonomy in Latin America. London: Ashgate, pp. 207-225.

. (2017). Chile y el Reino Unido: vaivenes de una relación diplomática no siempre tan cordial (1970-1980). Estudios Internacionales.Santiago de Chile, n. 186, pp. 9-38.

- y NAVARRO, Juan José (2018). El Servicio Universitario Mundial (SUM) en América Latina. Filantropía: educación, derechos humanos y lucha por la democracia. En MORALES MARTÍN, Juan Jesús (Comp.). Filantropía, ciencia y universidad: nuevos aportes y análisis sociohistóricos sobre la diplomacia académica en América Latina. Santiago de Chile: Escuela de Sociología, Universidad Católica Silva Henríquez, pp. 251-282.

BOLZMAN, Claudio (2006). De los europeizados a los deslocalizados: una tipología de las migraciones sudamericanas hacia Europa. En DEL POZO ARTIGAS, José (Coord.) Exiliados, emigrados y retornados, chilenos en América y Europa, 19732004. Santiago de Chile: Ril Editores, pp. 13-36.

COLLIER, Simon y SATER, William (1998). Historia de Chile 1808-1994. Cambridge: Cambridge University Press.

FRANCO, Marina (2008). El Exilio, argentinos en Francia durante la dictadura. Buenos Aires: Siglo XXI Editores.

GARRETÓN, Manuel Antonio (1993). La crisis de la democracia, el golpe militar y el proyecto contrarrevolucionario. Santiago de Chile, Documento de Trabajo FLACSO, Programa Chile, Serie Estudios Políticos Nro. 30.

HUNEEUS, Carlos (2000). El régimen de Pinochet. Santiago de Chile: Editorial Sudamericana. 
. (2009). La Guerra Fría chilena. Gabriel González Videla y la Ley Maldita. Santiago de Chile: Random House.

JEDLICKI, Fanny (2007). De l'exile heroique a l'illégitimité du retornado. Les retours des familes de réfugiés chiliens en France. Anuario de Estudios Americanos. Sevilla, Vol. I, n. 63, pp. 87-110, enero-junio.

JENSEN, Silvian (2011). Exilio e Historia Reciente. Avances y perspectivas de un campo en construcción. Aletheia. v. 1, n. 2, pp. 1-21. Disponible en www.aletheia.fahce.unlp.edu.ar/splash. Acceso: 30 de Octubre de 2019.

JOLY, Daniele (1987). Britain and its Refugees: The case of Chileans. Migration, I(I) pp. 91-108, julio.

. (1996). Haven or Hell: Asylum Policy and Refugees in Europe, Oxford: MacMillan.

KAY, Diana (1987) Chileans in Exile. Private Struggles, Publiclives. London: Macmillan.

KECK, Margaret y SIKKINK, Kathryn (1998). Activis tbeyond borders: advocacy networks in international politics. New York: Cornell UniversityPress.

LAQUEUR, Walter (1994). La Europa de nuestro tiempo. Buenos Aires: Editorial Vergara.

LASTRA, Soledad y PEÑALOZA PALMA, Carla (2016). Asilos en dictaduras: chilenos en la embajada argentina. Perfiles Latinoamericanos, v. 24, n. 48, pp. 83109. Disponible en: doi: 10.18504/p12448-004-2016. Acceso: 30 de octubre de 2019.

MATONTI, Frédérique y POUPEU, Franck (2004). Le capital militant. Essai de définition. Actes de la recherche en Sciences Sociales. Paris, n. 155, pp. 5-12, diciembre.

MONTUPIL, Fernando (1993). Exilio, Derechos Humanos y Democracia, El Exilio Chileno en Europa, Santiago de Chile: Coordinación Europea de Comités Pro Retorno.

NAZER, Ricardo y ROSEMBLIT, Jaime (2000). Electores, sufragio y democracia en Chile. Una mirada, histórica. Revista Mapocho. Santiago de Chile, n. 48, pp. 215229, segundo Semestre.

NORAMBUENA, Carmen (2000) Exilio y retorno. Chile 1973-1994. En GARCÉS, M. y otros (Comp.) Memoria para un nuevo siglo. Chile, miradas a la segunda mitad del siglo XIX. Santiago de Chile: LOM Ediciones, Santiago de Chile.

ORELLANA, Patricio (1981). El exilio chileno, Sussex: Institute of Development Studies.

PAREDES, Héctor Alejandro (2007). Las condiciones de vida de los exiliados chilenos en Mendoza (1973-1989). Tesis (Doctorado en Historia) Universidad Nacional de la Plata, Mar del Plata, Argentina.

PÉREZ BARAHONA, Sergio (2003). El Estatuto de "Refugiado" en la Convención de Ginebra de 1951. Redur, La Rioja, pp. 227-250.

ROUQUIÉ, Alain (1981). Poder militar y sociedad política en la Argentina. Buenos Aires: Emecé.

SZNAJDER, Mario y RONIGER, Luis. (2007). Exiles comunities and their differential institutional dynamics: A comparative anylisis of the chileans and the uruguayan political diáspora. Revista de Ciencia Política. Santiago de Chile, v. 27, n. 001, pp. 43-66.

REBOLlEDO, Loreto (2006). Memorias del Desarraigo, Testimonios de exilios y retorno de hombres y mujeres de Chile. Santiago de Chile: Catalonia. 
YANKELEVICH, Pablo (2010) Ráfagas de un exilio. Argentinos en México 1974-1983. México: Fondo de Cultura Económica.

y JENSEN, Silvina (2007), Exilios. Destinos y experiencias bajo la dictadura militar. Buenos Aires: Ed. Libros del Zorzal.

\section{Entrevistas citadas}

COAD, Malcom (2008) Entrevista realizada por la autora, Santiago de Chile.

FILOCHOWSKI, Julian (2013) Entrevista telefónica realizada por la autora.

GATEHOUSE, Mike (2009). Entrevista realizada por la autora en Gales.

LEHMANN, David (2009) Entrevista realizada por la autora en Londres.

MARTIN, Gerad (2009) Entrevista realizada por la autora en Londres.

O’SHAUGHNESSY, Hugh, (2009) Entrevista realizada por la autora en Londres. . (2013) Entrevista telefónica realizada por la autora.

Artigo recebido em 12 de novembro de 2019.

Aprovado em 20 de novembro de 2019.

DOI:10.12957/intellectus.2019.47132 